\title{
HETEROSEXUAL SIGNALLING BY THE LIZARD ANOLIS CAROLINENSIS, WITH INTERSEXUAL COMPARISONS ACROSS CONTEXTS
}

by

\begin{abstract}
KIMBERLY S. ORRELL and THOMAS A. JENSSEN ${ }^{1,2)}$
(Department of Biology, Virginia Polytechnic Institute and State University, Blacksburg, Virginia 24061, USA)
\end{abstract}

(Acc. 31-III-2003)

\begin{abstract}
Summary
We quantified the structure and use of signals exchanged by males and females within the female-defence polygyny of the lizard, Anolis carolinensis. During heterosexual interactions, both sexes performed three kinds of stereotypic headbob displays (A, B, and C) with equal precision. These three display types were essentially identical to $\mathrm{A}, \mathrm{B}$, and $\mathrm{C}$ display types previously documented for both sexes during consexual contests, and for males when displaying alone (non-directed context). Therefore, there is no courtship-specific headbob display in A. carolinensis. Although interacting males and females displayed at a similar mean frequency ( $\sim 20$ displays $/ \mathrm{h}$ ), signalling was sexually dimorphic in that: (1) males used predominately $\mathrm{C}$ displays (89\%), whereas females used predominantly A and B displays (48\% and $50 \%$, respectively); (2) males extended their dewlaps with almost every display (98\%), whereas females extended their dewlaps with few displays $(<2 \%)$; (3) males sequenced $80 \%$ of displays in volleys of two or more displays, whereas females performed only $12 \%$ of displays in volleys; and (4) males concluded $22 \%$ of displays with shudderbobs (i.e. display modifier composed of shallow, quick, double bobs), whereas females never appended displays with shudderbobs. From field and laboratory data on A. carolinensis signal behaviour during other social contexts and the species' female-defence mating system, we interpret heterosexual signalling from a perspective of intrasexual selection to discuss the: (1) absence
\end{abstract}

1) Corresponding author; e-mail address: tjenssen@vt.edu

2) We thank D. Cunningham for assistance in videotaping; J. Congdon, J. Cranford, M. Lovern, and J. Walters for comments on the manuscript; and E. Smith at the Virginia Polytechnic Institute and State University (VPI \& SU) Statistical Consulting Center for advice on statistical procedures. Animals were maintained following the approved protocol by the VPI \& SU Animal Care and Use Committee. The study was supported by a Sigma Xi grant to K. Orrell, and by the Department of Biology, VPI \& SU. 
of a courtship-unique display, (2) physical structure of displays, (3) display repertoire size, and (4) likelihood of species and individual recognition. For advertising sexual identity, the antithetical use of display types and dewlap by the sexes was both redundant and equivocal. Dewlap size (seven fold smaller for an average sized female than an average sized male) is an honest signal for sexual identity, yet females avoid extending their dewlaps to males. Thus, we propose a female mimicry hypothesis for the pattern of heterosexual signalling. By signalling ambiguously, females permit female-sized adult males to mimic female displays, whereby females and small males derive an alternative mating option. Small males that signal deceptively to a larger territorial male could avoid eviction and practice kleptogamy with resident females.

\section{Introduction}

Animals signal one another to coordinate and influence the social activities that are critical to mating success. As such, sexual selection should affect most aspects of a communication system in ways that facilitate male and female reproductive success. Additionally, within given mating systems, sexual selection may vary between the sexes, resulting in some degree of sexual dimorphism in signalling structures, signal repertoires, and patterns of signal use (Andersson, 1994; Bradbury \& Vehrencamp, 1998). This is particularly true of polygynous mating systems, where polygynous males have much greater variance in reproductive success than females, and consequently experience stronger sexual selection than females (Bateman, 1948). Thus, males of polygynous systems usually have enhanced signals for consexual competition (i.e. intrasexually selected effects) and/or for mate attraction (i.e. intersexually selected effects). Conversely, females rarely show the same degree of signal elaboration as polygynous, conspecific males (Bradbury \& Vehrencamp, 1998) and may even lack signals analogous to those of males (e.g. Thornhill \& Alcock, 1983; Searcy \& Andersson, 1986; Searcy \& Yawasaka, 1994). Because general theorems of sexual selection predict obvious sexually dimorphic effects on their communication systems, polygynous species are useful subjects for examining signal evolution. Furthermore, by examining species with well documented mating systems, predictive models for signal evolution can be more easily derived and tested by accumulating case studies that relate specific signal traits used by males and females to their known social activities.

\section{The mating system}

The green anole lizard (Anolis carolinensis) is an excellent subject for the study of sexually selected effects on communication behaviour because its 
female-defence polygyny is well documented (e.g. Ruby, 1984; Jenssen \& Nunez, 1998; Jenssen et al., 2001) and provides the opportunity to examine male and female signal expression within an intrasexually selected mating system. DeCourcy \& Jenssen (1994) and Jenssen et al. (2000) analyzed consexual signalling by male and female $A$. carolinensis, and found that the structure and use of headbob displays largely followed expectations for signals that are subject to intrasexual selection. However, lacking robust models, clear predictions as to how heterosexual signalling should evolve within the intrasexually selected mating system of A. carolinensis were elusive. To clarify the selective effects on heterosexual signals and to suggest relevant hypotheses to guide our study, an understanding of the spatial and social organization of the sexes was critical.

Characterization of the A. carolinensis mating system begins with the distribution of reproductive females in space and time because the reproductive traits of females largely determine the reproductive response of males (e.g. Partridge \& Endler, 1987; Davies, 1991; Sutherland, 1996). As Emlen \& Oring (1977) modeled female-defence polygyny, individual males can control access to multiple females when reproductive females are spatially and temporally clumped. Spatially, females of A. carolinensis move from overwintering shelters into home ranges prior to the breeding season (Jenssen et al., $2001)$, then remain in relatively stable, small $\left(\sim 8 \mathrm{~m}^{3}\right)$, overlapping $(\sim 20 \%)$, and lightly defended ( $\sim$ one aggressive encounter/day) home ranges during the breeding season (Nunez et al., 1997; Jenssen \& Nunez, 1998). The small female home ranges and infrequent competitive interactions between neighbouring females suggest that resources needed for egg production are not critically limited (Jenssen \& Nunez, 1998), thus arguing against a resourcedefence strategy for males. Temporally, females have a long breeding season, laying single-egg clutches at about weekly intervals (Andrews, 1985a; Michaud, 1990) throughout a 4-month period (Jenssen et al., 1995).

In response to clumped, sedentary, and iteroparous females, males attempt to monopolize multiple females by means of long-term territorial defence (Ruby, 1984; Jenssen et al., 1995). Inter-male contests for habitat containing females result in a 1:3 male-to-female polygyny ratio in populations with $1: 1$ adult sex ratios (Ruby, 1984; Jenssen et al., 1995). As a consequence of female-defence territoriality, the potential reproductive rate among territorial males is positively correlated with male body size, size of male territory, number of defended (i.e. resident) females, and duration of the male on his 
territory (Ruby, 1984; Jenssen \& Nunez, 1998). Selection for inter-male aggression in A. carolinensis may contribute to prominent sexual dimorphism. In comparison to females, males are 30-40\% larger in body mass (Jenssen et al., 1995; Orrell, 2002), have seven-fold greater dewlap area $\left(1.52 \mathrm{~cm}^{2}\right.$ versus $0.22 \mathrm{~cm}^{2}$; Jenssen et al., 2000), have eight-fold greater territory volume $\left(69 \mathrm{~m}^{3}\right.$ versus $\left.8 \mathrm{~m}^{3}\right)$, move six-fold greater distances $(27 \mathrm{~m} / \mathrm{h}$ versus $4 \mathrm{~m} / \mathrm{h}$ ), display seven-fold more frequently (100 displays/h versus 14 displays $/ \mathrm{h}$ ), and spend a 30 -fold greater proportion of the day in consexual disputes $(9.2 \%$ versus $0.03 \%$ ) (Jenssen et al., 1995; Nunez et al., 1997; Jenssen \& Nunez, 1998).

\section{Mate choice}

Within the female-defence polygyny of A. carolinensis, the mechanism of mate choice differs between the sexes. Females appear to employ indirect mate choice (i.e. passive choice, sensu Wiley \& Poston, 1996). Females, by being sedentary (Nunez et al., 1997) and closely spaced (Jenssen \& Nunez, 1998), attract local males. Ensuing inter-male contests produce a minority of males who can establish and maintain stable territories containing multiple females (Ruby, 1984). Territorial males then serve as the primary mates for their respective resident females (Jenssen \& Nunez, 1998). Thus, offspring of resident females receive paternal traits that were selected for by territorial contests (e.g. large body size, aggressiveness, fighting ability, and a robust physiology for stamina and good health). Because they do not actively select mates, A. carolinensis females fit the neutral-mate-choice model (sensu Lightbody \& Weatherhead, 1988; Jenssen \& Nunez, 1998).

Mate choice by males appears to emphasize quantity of mates, and not quality. Jenssen \& Nunez (1998) found no evidence for assortative mate choice for selected variables (i.e. male body size and territory size were not correlated with female body size, home-range size, and potential reproductive rate). However, Jenssen \& Nunez did find that male potential reproductive rate was correlated with number of defended females. A quantitative response to mate choice was further documented for males by their pronounced preference for novel females over resident females (Orrell \& Jenssen, 2002).

\section{Guiding hypotheses}

Given the details of the species' mating system (above), we pose three general hypotheses to guide our analysis of heterosexual signalling. First, we 
predict no courtship-unique signals in either sex. Selection for a courtshipunique signal would most likely occur where one or both sexes were mobile and dependent on an attraction signal by the opposite sex for localization of potential mates (e.g. female frogs moving to calling males, Howard, 1978; or male snakes moving to pheromone-emitting females, Ford, 1986). Selection for a mate attraction signal would be particularly pronounced if one or both sexes had a limited temporal window for reproduction. In contrast to the latter conditions, females of $A$. carolinensis establish their home ranges before breeding begins. Then local males become territorial and, for up to four months, defend and mate primarily with females already resident within their patrol areas (Jenssen \& Nunez, 1998; Jenssen et al., 2001). Thus, where long-term mates occur in close proximity to one another, a courtship attraction signal would be superfluous.

Second, we predict that the structural features of displays used during the heterosexual context should borrow from heavily selected displays used for non-directed (i.e. territorial advertisement) and consexual contexts (e.g. DeCourcy \& Jenssen, 1994; Jenssen et al., 2000). Given the reproductive importance of consexual contests in the mating system of A. carolinensis, especially for males, signal design and display repertoire should strongly reflect the influence of intrasexual selection. Conversely, because there is little evidence to suggest that mating decisions of either sex are based on display use during heterosexual interactions (Jenssen \& Nunez, 1998; Orrell \& Jenssen, 2002), intersexual selection on signals should be relatively weak. Thus, we expect that intrasexually selected signal traits may be conserved in signals used during heterosexual interactions. Berglund et al. (1996) make a similar argument in their evolutionary model for signals that serve in both consexual and heterosexual contexts.

Third, we expect that if males and females share a common display repertoire that is primarily influenced by intrasexual selection among males (e.g. Jenssen et al., 2000), then each sex should use the signals in their shared repertoire in a sexually dimorphic manner. Thus, potential functions for heterosexual signal use (e.g. identifying species, sex, individuals, and interest in mating) may be accomplished by the choice and frequency of signals used.

To test our three predictions, we: (1) describe the structure and use of heterosexual display behaviour by A. carolinensis; (2) compare signal behaviour during heterosexual interactions with that of consexual and non-directed social contexts; and (3) draw inferences on possible signal function relative to 
the mating system of $A$. carolinensis. Ultimately, our analysis will initiate generalizations for the evolution of heterosexual signals within a seemingly male-controlled mating system.

\section{Methods}

Seventeen adult males [mean \pm SE snout-vent length $(\mathrm{SVL})=58.7 \pm 1.24 \mathrm{~mm}$ ] and 17 adult females (mean $\pm \mathrm{SE} \mathrm{SVL}=50.7 \pm 1.76 \mathrm{~mm}$ ) of A. carolinensis were collected during the breeding season (April-July) from the Savannah River Site in Aiken, South Carolina, and brought to our laboratory at Virginia Tech. They were grouped into 17 male/female pairs, with each pair held separately in $0.6 \mathrm{~W} \times 0.6 \mathrm{H} \times 0.7 \mathrm{~L} \mathrm{~m}$ wooden cages for $1-3$ weeks prior to observations. For observations, each pair was moved to a $0.6 \mathrm{~W} \times 0.6 \mathrm{H} \times 1.2 \mathrm{~L}$ m wooden enclosure with a front wall of glass. The glass was slanted away from the cage at the top, and covered on the inner surface with a fine nylon screen to minimize the prospect that lizards might see and respond to their own reflections. All cages and the observation enclosure were furnished with tree trunks, branches, artificial foliage, and soil substrate, and illuminated by $1.3 \mathrm{~m}$ long, $40 \mathrm{~W}$ fluorescent bulbs and $150 \mathrm{~W}$ incandescent floodlights (200-300 lux; LI-COR model LI-185B photometer). The photoperiod was kept on a $12 \mathrm{~L}: 12 \mathrm{D}$ cycle to facilitate reproductive condition (Licht, 1971). Cage temperatures were about $24^{\circ} \mathrm{C}$ at night, and $28-35^{\circ} \mathrm{C}$ during the day, but could reach $42^{\circ} \mathrm{C}$ directly under a floodlight. Vitamin-dusted crickets, waxworms, and sprayed water were provided daily.

We conducted 17 trials of heterosexual interactions using 17 separate pairs of lizards. For each trial, we moved a male/female pair to the observation enclosure, and allowed the lizards three days to acclimate. Then we videotaped spontaneous interactions for three hours from a darkened blind $1.5 \mathrm{~m}$ in front of the observation cage, through a $5 \mathrm{~cm} \mathrm{H} \times 140 \mathrm{~cm} \mathrm{~L} \mathrm{opening.}$ We used two cameras (Panasonic Model WV-1550 and Vicon 16-160 mm zoom lenses) to provide enlarged images of each lizard. Output from the two cameras was simultaneously recorded to a video cassette recorder (Panasonic Model AG-1950) with a split screen generator (Vicon Model V270SP, P8). Elapsed time in $0.01 \mathrm{~s}$ intervals was also recorded to the videotape by a time-date generator (Odetics Model G-77).

The most complex and almost exclusive class of signals performed were headbobbing displays. The quantitative analysis of these displays required frame-by-frame analysis. We followed the methods of DeCourcy \& Jenssen (1994) by plotting the head amplitude and dewlap extension over time. The resulting display-action-pattem graphs (DAP graphs, sensu Carpenter \& Grubitz, 1961) were divided into naturally occurring units of bobs and interbob pauses. The cadence (temporal and spatial pattern) of bobs and pauses within a display was used to sort the displays into several reoccurring patterns that we refer to as 'display types'. Following the convention of DeCourcy \& Jenssen (1994), display types were labelled by a letter designation (e.g. A, B, C), and display units were numbered based on a perceived homology among display types (see DeCourcy \& Jenssen, 1994). Analysis of each display type concentrated on 'core' units (i.e. units always performed for a display type, sensu Jenssen, 1977). Display unit durations were measured to the nearest $0.033 \mathrm{~s}$. We limited DAP graph analysis of male displays to five subjects (chosen at random from the 17 males) because male headbob displays have previously been analyzed (e.g. DeCourcy \& Jenssen, 1994; Lovern et al., 1999; Jenssen et al., 2000). The remainder of male displays were classified into types by visual inspection of the videotape record. 
Headbob displays were analyzed for stereotypy using descriptive statistics [mean \pm standard error (SE) and coefficient of variation ( $\mathrm{CV}=\mathrm{SD} /$ mean * 100)]. As a convention, we considered behavioural units with a CV $<35 \%$ to be highly stereotyped (Barlow, 1977). Comparisons were made with non-parametric Kruskal-Wallis tests. Sequential Bonferroni adjusted $p$-values (SBON) were used for multiple comparisons within a group to reduce the possibility of type I errors (Rice, 1989). For sex and context comparisons, a mean value for each subject was used as an individual observation to eliminate bias due to unequal numbers of sample sizes among subjects. Nested analysis of variance quantified sources of display variance (e.g. context, sex, subject, and error), and multivariate discriminant procedures were used to compare the displays of individual subjects. All statistics were computed with SAS version 6.12 (SAS Institute, Inc., 1989), and were two-tailed with an overall $\alpha=0.05$.

For each display performance, the following variables were recorded from videotapes: (1) signaller identification; (2) signaller sex; (3) display type; (4) whether the dewlap was extended (i.e. coloured throat fan adapted for signalling, described by Bels, 1990; Font \& Rome, 1990); (5) whether display was performed singly or as part of a volley (i.e. two or more displays $<2 \mathrm{~s}$ apart); (6) if display was part of a volley, its position in the sequence of displays; and (7) whether display was accompanied by non-headbob movements and postures (i.e. dynamic and static modifiers associated with the display behaviour, sensu Jenssen, 1979). In addition, because signal use may be correlated with the distance between signaller and recipient, we estimated the inter-subject separation distance for each display performance using a tape measure affixed to the bottom front of the observation cage. Displays were assigned to one of five classes of inter-subjectseparation distances: $1(1-20 \mathrm{~cm}), 2(21-40 \mathrm{~cm})$, $3(41-60 \mathrm{~cm}), 4(61-80 \mathrm{~cm})$, and $5(>80 \mathrm{~cm})$.

We compared display structure and use during heterosexual interactions with those from three other social contexts: male non-directed context (i.e. male-alone; DeCourcy \& Jenssen, 1994), male-male context (DeCourcy \& Jenssen, 1994), and female-female context (Jenssen et al., 2000). Inter-study comparisons were facilitated by the fact that all studies were conducted in the same laboratory, and used the same housing and observation conditions, recording equipment, recorded variables, and analysis protocol.

\section{Results}

\section{Display types}

DAP graph analyses were made on 336 female displays and 126 male displays from heterosexual interactions. Three distinct display type patterns (i.e. A, B, and C) were found (Fig. 1). Males and females performed each display type with near identical precision. The core portion of all three display types ended with unit 11 , followed by $0-4$ optional units (98\% of displays included or ended with unit 13 , and $22 \%$ of displays ended with unit 15). When comparing durations of the 33 homologous units, none significantly differed between the sexes (Kruskal-Wallis, SBON, $p>0.001$ ), nor did the total duration of display cores (Kruskal-Wallis, $p>0.06$; Table 1). 
TABLE 1. Displays performed by Anolis carolinensis during the heterosexual context

\begin{tabular}{|c|c|c|c|c|c|c|c|c|c|}
\hline \multicolumn{2}{|c|}{ Display } & \multicolumn{3}{|c|}{ Female Displays } & \multicolumn{3}{|c|}{ Male Displays } & \multicolumn{2}{|c|}{$\begin{array}{c}\text { Kruskal-Wallis } \\
\text { tests }\end{array}$} \\
\hline Type & Unit & Mean (s) & SE & $\mathrm{CV}$ & Mean (s) & SE & $\mathrm{CV}$ & $H$ & $p$ \\
\hline \multirow[t]{12}{*}{ A } & 1 & 0.217 & 0.006 & 12.3 & 0.176 & 0.011 & 14.3 & 8.18 & 0.004 \\
\hline & 2 & 0.106 & 0.008 & 32.6 & 0.112 & 0.026 & 52.9 & 0.04 & 0.845 \\
\hline & 3 & 0.138 & 0.002 & 6.0 & 0.142 & 0.012 & 18.1 & 0.00 & 0.969 \\
\hline & 4 & 0.185 & 0.010 & 21.8 & 0.139 & 0.017 & 27.7 & 4.00 & 0.046 \\
\hline & 5 & 0.165 & 0.005 & 11.7 & 0.167 & 0.024 & 31.6 & 0.68 & 0.410 \\
\hline & 6 & 0.338 & 0.016 & 19.4 & 0.337 & 0.052 & 34.7 & 0.01 & 0.906 \\
\hline & 7 & 0.126 & 0.003 & 8.6 & 0.128 & 0.008 & 14.0 & 0.04 & 0.844 \\
\hline & 8 & 0.087 & 0.004 & 20.8 & 0.076 & 0.006 & 18.0 & 1.88 & 0.170 \\
\hline & 9 & 0.123 & 0.002 & 6.8 & 0.123 & 0.005 & 8.6 & 0.00 & 1.000 \\
\hline & 10 & 0.192 & 0.007 & 15.6 & 0.160 & 0.033 & 46.5 & 0.67 & 0.411 \\
\hline & 11 & 0.123 & 0.003 & 10.5 & 0.118 & 0.007 & 12.7 & 0.39 & 0.530 \\
\hline & Total & 2.186 & 0.042 & 8.0 & 1.974 & 0.038 & 3.9 & 3.54 & 0.060 \\
\hline \multirow[t]{10}{*}{ B } & 1 & 0.159 & 0.003 & 6.6 & 0.148 & 0.005 & 7.4 & 2.46 & 0.117 \\
\hline & 2 & 0.166 & 0.012 & 30.3 & 0.151 & 0.007 & 10.6 & 0.61 & 0.433 \\
\hline & 5 & 0.343 & 0.011 & 13.8 & 0.388 & 0.014 & 8.2 & 4.65 & 0.031 \\
\hline & 6 & 0.245 & 0.014 & 24.2 & 0.298 & 0.014 & 10.6 & 2.71 & 0.100 \\
\hline & 7 & 0.148 & 0.004 & 11.1 & 0.122 & 0.007 & 12.0 & 5.72 & 0.017 \\
\hline & 8 & 0.082 & 0.004 & 19.3 & 0.084 & 0.005 & 12.7 & 0.00 & 1.000 \\
\hline & 9 & 0.144 & 0.003 & 8.2 & 0.131 & 0.009 & 15.1 & 3.12 & 0.077 \\
\hline & 10 & 0.281 & 0.010 & 15.1 & 0.261 & 0.022 & 19.2 & 0.26 & 0.611 \\
\hline & 11 & 0.147 & 0.004 & 12.0 & 0.137 & 0.007 & 11.1 & 0.96 & 0.327 \\
\hline & Total & 2.107 & 0.045 & 8.9 & 1.986 & 0.034 & 3.9 & 1.12 & 0.290 \\
\hline \multirow[t]{8}{*}{$\mathrm{C}$} & 5 & 0.452 & 0.028 & 12.4 & 0.516 & 0.023 & 10.1 & 2.16 & 0.142 \\
\hline & 6 & 0.265 & 0.019 & 14.4 & 0.198 & 0.037 & 42.2 & 1.51 & 0.219 \\
\hline & 7 & 0.157 & 0.008 & 10.5 & 0.146 & 0.006 & 9.1 & 0.56 & 0.455 \\
\hline & 8 & 0.204 & 0.015 & 14.3 & 0.192 & 0.007 & 7.9 & 0.54 & 0.462 \\
\hline & 9 & 0.169 & 0.022 & 25.7 & 0.178 & 0.005 & 6.7 & 1.50 & 0.221 \\
\hline & 10 & 0.176 & 0.013 & 15.3 & 0.183 & 0.014 & 16.6 & 0.00 & 1.000 \\
\hline & 11 & 0.124 & 0.008 & 13.3 & 0.127 & 0.002 & 3.6 & 0.29 & 0.592 \\
\hline & Total & 2.144 & 0.038 & 3.5 & 2.005 & 0.059 & 6.6 & 2.16 & 0.142 \\
\hline
\end{tabular}

Mean, standard error (SE), and coefficient of variation (CV) for display unit durations (units 1-11) and total display duration (Total; all units in a display, through unit 15) of A, B, and $\mathrm{C}$ displays performed by captive Anolis carolinensis during the heterosexual context. Intersexual comparisons were statistically insignificant at $p<0.001$ (sequential Bonferroni method; Rice, 1989). 


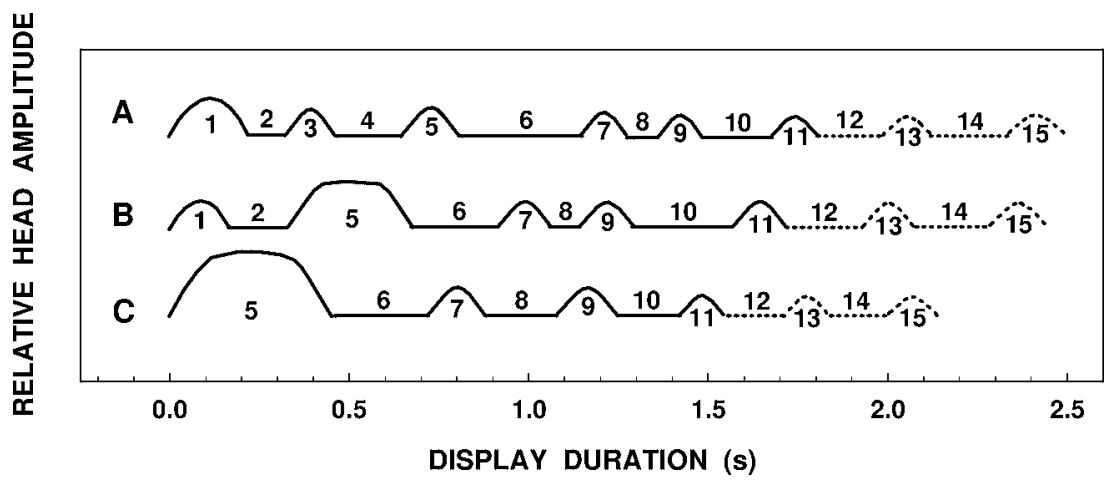

Fig. 1. Display Action Pattern (DAP) graphed representations of type A, B, and C displays of captive Anolis carolinensis during the heterosexual context, with relative head amplitude plotted over time. Odd numbers label bob units, even numbers label inter-bob pause units, solid lines indicate core units, and broken lines indicate optional units.

The cadence patterns of $\mathrm{A}, \mathrm{B}$, and $\mathrm{C}$ displays performed during courtship were nearly identical to those previously described for consexual male and consexual female contexts (Jenssen et al., 2000). Of the 48 unit durations and six total display durations compared, only units 8 and 9 of female A displays and the total duration of female A displays were significantly different between heterosexual and consexual contexts (Kruskal-Wallis, SBON, $p=0.017-0.002$; Figs 2 and 3). However, in spite of similar durations for homologous units, there was a significant trend for male and female displays performed during courtship to have shorter bob units (for 19 of 24 units; Chisquare test, $\chi^{2}=8.2, p<0.004$ ), longer pause units (for 22 of 24 units; $\chi^{2}=16.7, p<0.001$ ), and a longer total duration of units 1-10 (for 6 of 6 comparisons) than displays during consexual contexts (Figs 2 and 3).

\section{Display stereotypy}

Unit durations within $\mathrm{A}, \mathrm{B}$, and $\mathrm{C}$ displays were highly stereotyped in both sexes. Within-subject unit CVs (calculated for each subject separately) ranged from 0 to $71.7 \%$. Of the 578 display units analyzed, 565 had CV values $<35 \%$. Among-subject $\mathrm{CV}$ values, where intra-subject mean unit durations were used as a single datum, ranged from 3.6 to $52.9 \%$ (Table 1), and 51 of 54 unit $\mathrm{CV}$ values were $<35 \%$. There was a significant trend for bob units (odd-numbered units) to be more stereotypic (i.e. lower CV values) than pause units (even-numbered units) (for 22 of 24 units, a frequency not expected by chance; Chi-square test, $\left.\chi^{2}=16.7, p<0.001\right)$. 


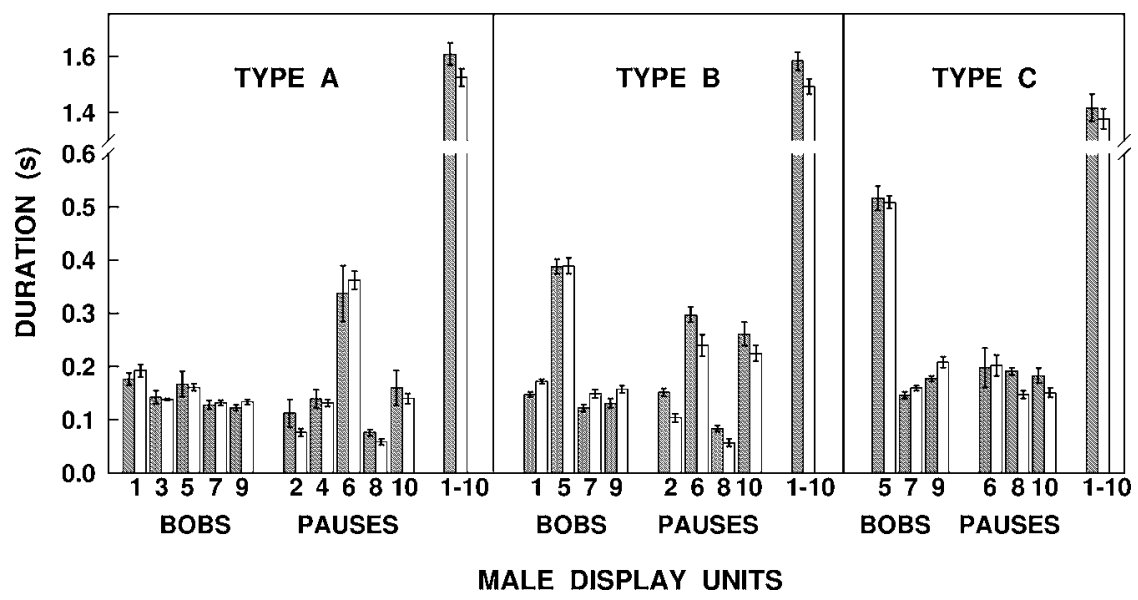

Fig. 2. Comparison of mean unit durations $( \pm \mathrm{SE})$ of type $\mathrm{A}, \mathrm{B}$ and $\mathrm{C}$ displays performed by captive male Anolis carolinensis during heterosexual (shaded) and consexual (open) contexts (within-subject means used as variables). None of the units compared were significantly different between contexts (Kruskal-Wallis tests, $p>0.002$; sequential Bonferroni adjusted $p$-values). Sample sizes for the heterosexual context included 31 A, $29 \mathrm{~B}$, and $66 \mathrm{C}$ displays performed by 5 males, and for the consexual context included $47 \mathrm{~A}, 49 \mathrm{~B}$, and $76 \mathrm{C}$ displays performed by 8 males.

\section{Sources of display unit variance}

Combining our data with those available for males and females during consexual contexts (see Methods), we used a nested ANOVA procedure to partition display unit variance according to context, sex, among-subject, and within-subject components ( $F$-tests were not computed due to unbalanced data). Context (e.g. heterosexual, consexual male, and consexual female) and sex contributed little to unit variance of each display type; the mean unit variance attributed to context ranged from 10.4 to $19.3 \%$, and to sex ranged from 6 to $15 \%$ (Fig. 4). Differences among and within individual subjects were the two largest sources of display unit variance. Within each display type, the average proportion of unit variance due to differences among subjects ranged from 25 to $33 \%$, and that due to differences within subjects was slightly greater, ranging from 37 to $50 \%$ (Fig. 4). When display unit variance was examined by bobs and pauses, bob unit durations tended to vary less among subjects than within subjects ( 10 of 12 bob units) and, conversely, pause unit durations tend to vary more among subjects than within subjects (7 of 12 pause units; Fig. 4). 


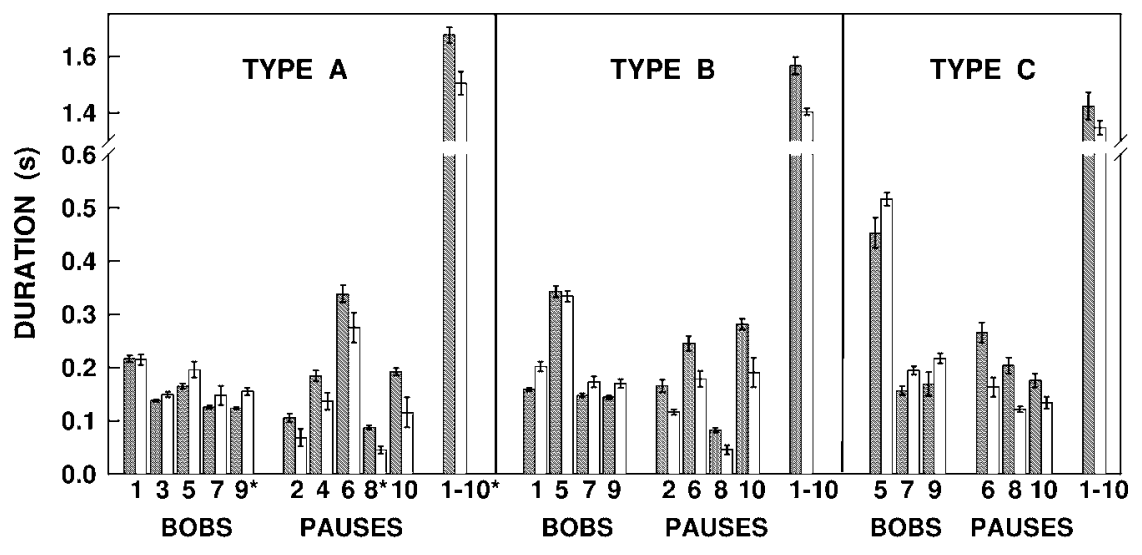

FEMALE DISPLAY UNITS

Fig. 3. Comparison of mean unit durations $( \pm \mathrm{SE})$ of type $\mathrm{A}, \mathrm{B}$ and $\mathrm{C}$ displays performed by captive female Anolis carolinensis during heterosexual (shaded) and consexual (open) contexts (within-subject means used as variables). Units marked with an asterisk (*) were significantly different between contexts (Kruskal-Wallis tests and sequential Bonferroni adjusted $p$-values). Sample sizes for the heterosexual context included $163 \mathrm{~A}, 165 \mathrm{~B}$, and $7 \mathrm{C}$ displays performed by 17 females, and for the consexual context included 7 A, 20 B, and 105 $\mathrm{C}$ displays performed by 16 females.

\section{Individual differences}

Although displays were highly stereotyped, inter-subject differences in display cadence were sufficient that a multivariate discriminant analysis could frequently identify the displays of individual subjects. Using units 1-13 of male and female displays performed during the heterosexual context, nearest neighbour discriminant analysis correctly identified the subjects for $86.4 \%$ of A displays, $83.1 \%$ of B displays, and $79.2 \%$ of $\mathrm{C}$ displays.

\section{Display modifiers}

Besides stereotyped headbob displays, the only other obvious signal performed was a display modifier (i.e. an optional movement or posture added to a headbob display, sensu Jenssen, 1977). This modifier, performed only by males, was appended to the end of a display, and fits the description of 'shudderbob' (sensu Tinkle, 1967). Shudderbobs were a variable series of shallow double bobs that terminated $22 \%$ of male displays. Shudderbob amplitude was $30-50 \%$ that of the last bob in the display (Fig. 5). From 15 DAP graphed 


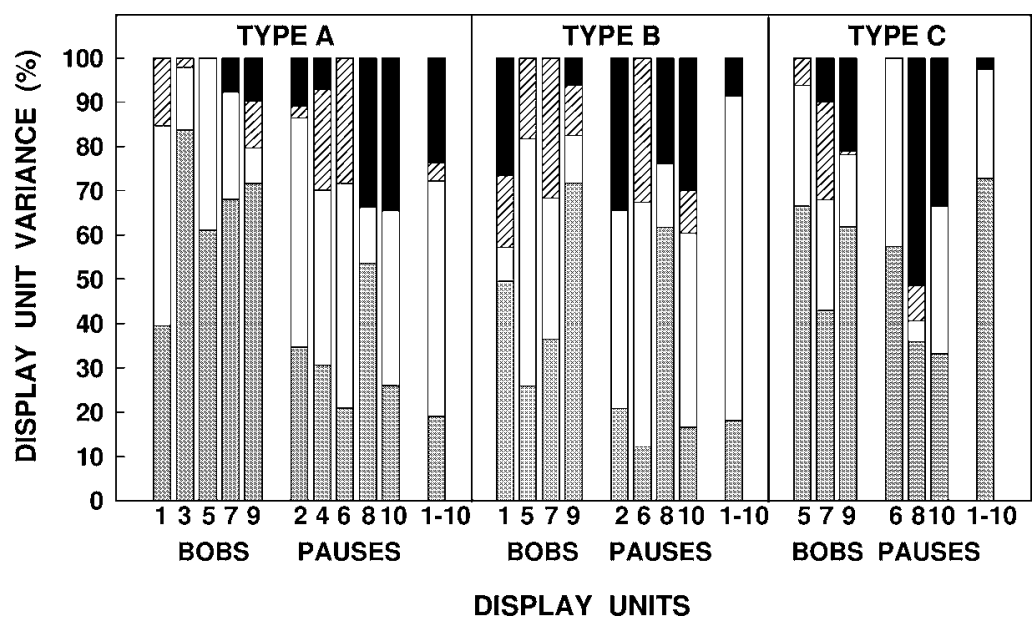

Fig. 4. Proportion of variance found in unit durations of captive Anolis carolinensis type A, $\mathrm{B}$ and $\mathrm{C}$ displays attributed to context (black - $\mathbf{-}$ ), sex (striped - $\square$ ), and within-subject (1:) components by a nested analysis of variance. Sample sizes for the heterosexual context included $163 \mathrm{~A}, 165 \mathrm{~B}$, and $7 \mathrm{C}$ displays performed by 17 females, and $31 \mathrm{~A}, 29 \mathrm{~B}$, and $66 \mathrm{C}$ displays performed by 5 males. Sample sizes for the consexual context included $7 \mathrm{~A}, 20 \mathrm{~B}$, and $105 \mathrm{C}$ displays performed by 16 females, and $47 \mathrm{~A}, 49 \mathrm{~B}$, and $76 \mathrm{C}$ displays performed by 8 males.

sequences, shudderbobs: began after a brief pause (0.15 \pm SE $0.01 \mathrm{~s})$ following the last bob of a display (i.e. unit 11, 13, or 15); averaged $5.5 \pm 0.38$ bobs in a sequence; and were composed of individual bobs of short, variable duration (0.1-0.6 s/bob). Shudderbobs were not associated with any particular display type, being performed with $28 \%$ of $\mathrm{A}, 26 \%$ of $\mathrm{B}$, and $23 \%$ of $\mathrm{C}$ displays (Cochran-Mantel-Haenszel Statistic, $F=1.03, p>0.31$ ). Shudderbobs accompanied $12 \%$ of single displays (i.e. not in a volley) and $25 \%$ of volleyed displays. When a display within a volley was accompanied by shudderbobs, the position of the modified display within the volley was random (Cochran-Mantel-Haenszel Statistic, $F=0.008, p>0.92$ ). Female displays were not accompanied by any modifiers.

\section{Signal use}

Although both sexes performed about 20 displays per hour (19.2 \pm 3.40 displays/h for males, $21.7 \pm 3.12$ displays/h for females; Table 2) and tended to perform displays at short $(0-60 \mathrm{~cm})$ rather than long $(>80 \mathrm{~cm})$ inter-subject 


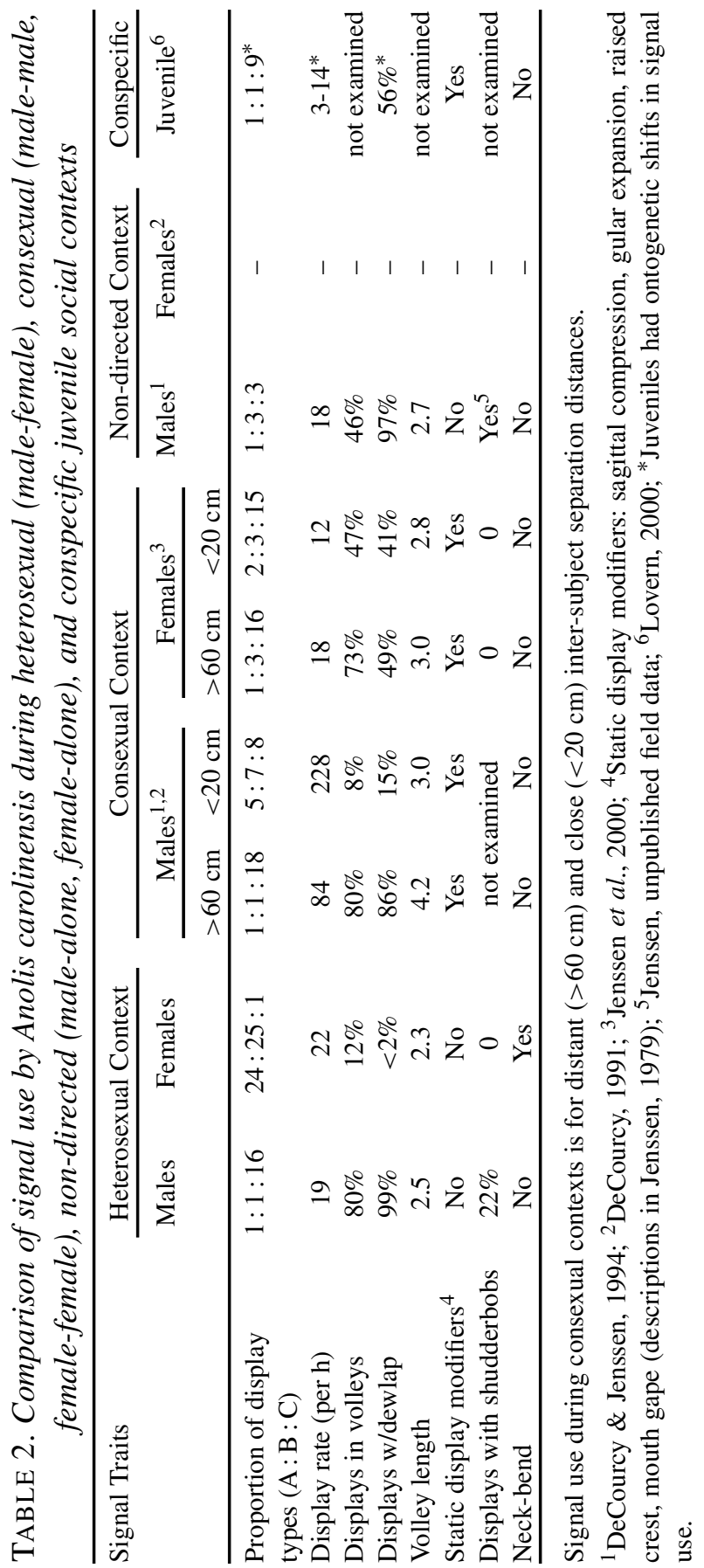




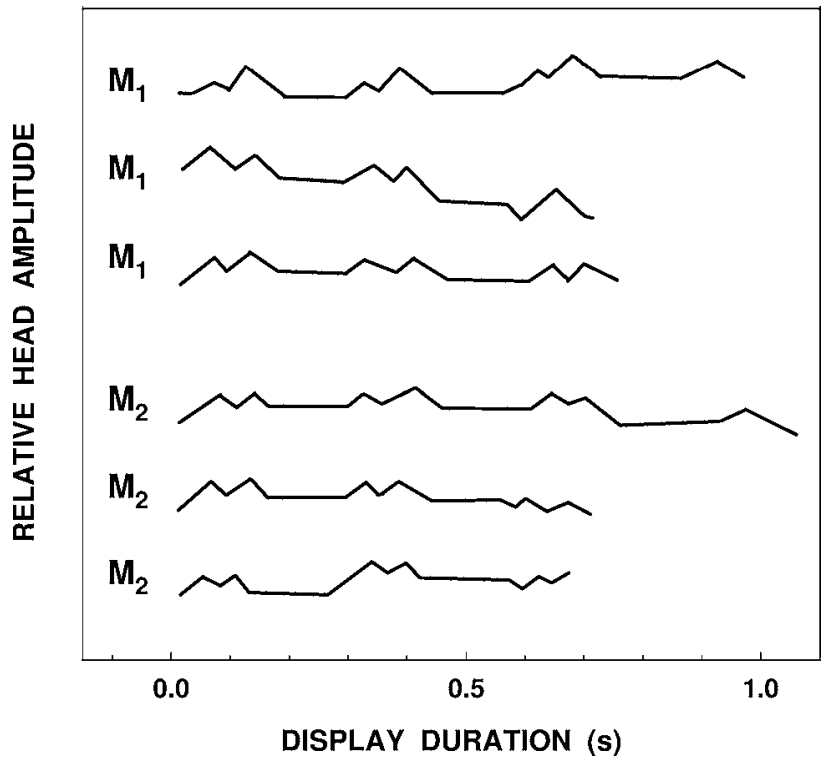

Fig. 5. Display Action Pattern (DAP) graphed representations of shudderbobs performed by two captive male Anolis carolinensis ( $\mathrm{Ml}$ and M2).

separation distances (Cochran-Mantel-Haenszel Statistic, $F=8.79$ for females, 5.01 for males, $p<0.025$; Fig. 6), we found four pronounced sexual dimorphisms in signal use. First, females performed mostly A and B displays (A : B : C ratio of $24: 25: 1$ ), while males performed mostly $\mathrm{C}$ displays (A : B : C ratio of 1:1:16; Fig. 6, Table 2). Second, females mostly performed displays singly (88\%) rather than in volleys (12\%), whereas males performed most displays in volleys (80\%; Fig. 7, Table 2). Third, dewlap extension rarely accompanied female displays $(<2 \%)$, and almost always accompanied male displays (99\%; Table 2). Fourth, females used no modifiers with their displays, while males terminated $22 \%$ of their displays with shudderbobs (Fig. 5, Table 2).

\section{Possible correlates of signal frequency}

We examined whether the frequency of male signalling might reflect relative arousal level or body condition. Our assumptions were that display rate should correlate positively with motivation level, and good body condition (due to energy reserves) should facilitate greater levels of signalling. If the assumptions are correct, display rate should covary with other signalling 


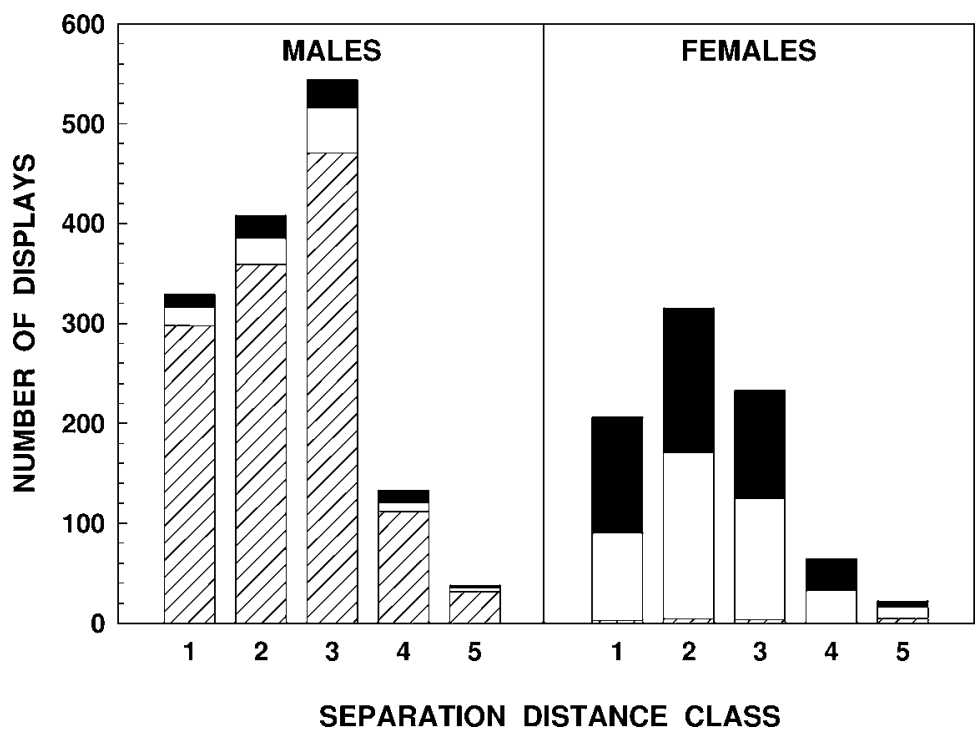

Fig. 6. Number of type A (black - - 1 ), B (open - $\square$ ), and C (striped - display patterns performed by 17 male and 17 female captive Anolis carolinensis divided into the following five classes of separation distance: (1) $0-20 \mathrm{~cm}$, (2) $21-40 \mathrm{~cm}$, (3) $41-60 \mathrm{~cm}$, (4) $61-80 \mathrm{~cm}$, and $(5)>80 \mathrm{~cm}$.

variables, and/or body condition should covary with signalling behaviour. Under our laboratory conditions, however, we found neither to be the case. Male display rate did not significantly correlate with: the tendency to display in volleys, the use of shudderbobs, female display rate, female neck-bends (sign of sexual receptivity, Crews, 1973a), or with copulation (Fisher's exact test, $p=0.6-1.0)$. Similarly, neither male body mass nor body condition (residuals resulting from $\ln$ body mass regressed by $\ln$ SVL) correlated with male display rate, proportion of displays in volleys, or proportion of displays with shudderbobs (Fisher's exact test, $p=1.0$ ).

\section{Heterosexual signal use compared with other social contexts}

Display rates were similar for both sexes and during all social contexts (1222 displays/h; Table 2), except when males displayed at other males. Male display rates during consexual encounters increased more than 10-fold over other contexts, especially for males in close proximity (228 displays $/ \mathrm{h}$ ).

Although both sexes used A, B, and C displays across all social contexts (Table 2), the use of display types varied with sex and social context. Males 


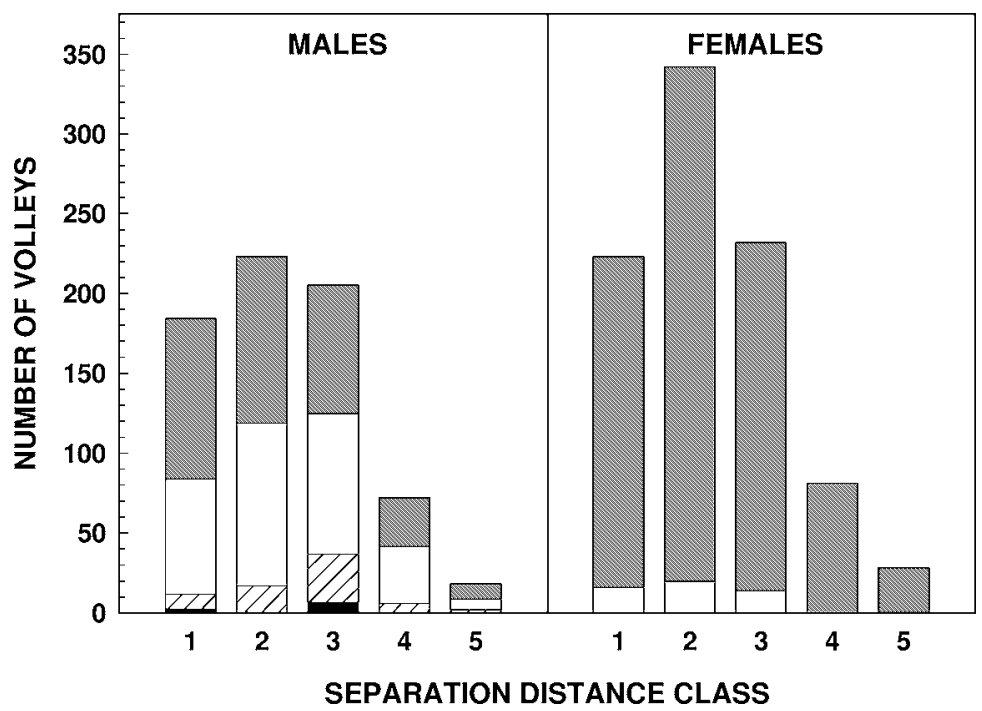

Fig. 7. Number of single displays (shaded displays (volley of 2-4 displays - open — $\square$, volley of 5-7 displays - striped 8-17 displays - black - D) performed by 17 male and 17 female captive Anolis carolinensis at each of the following five classes of separation distance: (1) $0-20 \mathrm{~cm}$, (2) $21-40 \mathrm{~cm}$, (3) $41-60 \mathrm{~cm}$, (4) $61-80 \mathrm{~cm}$, and (5) $>80 \mathrm{~cm}$.

used nearly equal proportions of all three display types when alone (i.e. non-directed context), but performed primarily $\mathrm{C}$ displays when signalling towards females and males at a distance. During close consexual encounters, however, males within biting distance increased the proportion of $\mathrm{A}$ and $\mathrm{B}$ displays. In contrast to males, females did not display when alone (i.e. nondirected context), used almost exclusively A and B displays towards males, largely performed $\mathrm{C}$ displays towards other females, and did not increase the use of A and B displays when approaching other females within biting distance.

The use of dewlap extension with displays also differed with sex and social context (Table 2). For males, dewlap extension almost always accompanied displays during the non-directed context, towards females, and towards other males at a distance (Table 2). However, when males approached to within biting distance of other males, their dewlaps were rarely extended. In contrast to males, female dewlap extension was rare when signalling to males, but frequent when signalling other females. Females did not decrease dewlap use during close consexual encounters. 
Displays were sequenced in volleys by both sexes, but volleys were used most frequently by males when signalling females and when signalling other males at a distance (Table 2). The lowest proportion of volleyed displays was that of females towards males, and of males during close consexual encounters. Both sexes employed numerous modifiers during consexual displaying, and two signals appeared sex-specific. The shudderbob modifier seems restricted to male displays during heterosexual and non-directed contexts, and neckbending appears to be a female signal of sexual receptivity (Table 2).

\section{Discussion}

During heterosexual interactions, both sexes performed the same three cadence patterns of A, B, and C headbob displays (Fig. 1), and performed these displays with equal stereotypic precision (Table 1). This observation corrects a misconception introduced by prior studies (e.g. Crews, 1973b, 1975; Greenberg, 1977) that displays of female A. carolinensis lack the distinct patterns and stereotypy typical of male displays. Furthermore, the A, B, and $\mathrm{C}$ display patterns performed during heterosexual interactions were virtually indistinguishable from the $\mathrm{A}, \mathrm{B}$, and $\mathrm{C}$ display patterns documented during other social contexts for A. carolinensis. Our analysis found little variance in display structure attributed to social context when comparing displays performed during heterosexual interactions with those reported by Jenssen et al. (2000) for consexual male and consexual female interactions (Figs 2-4). That the sexes of $A$. carolinensis use the same A, B, and $\mathrm{C}$ headbob displays across different social contexts demonstrates why labelling displays with a functional epithet can be inappropriate. Functional labelling carries the presumption that other possible functions for the signal have been eliminated. If the presumed function is incorrect, the label prevents or misleads further research and obscures evolutionary interpretations of a species' communication system (sensu Tinbergen, 1951).

To make informed inferences about social functions and selective benefits associated with $A$. carolinensis displays, interpretations are best made within the context of the species' mating system and within a more natural social setting than that of our manipulated social contexts within enclosures. Fortunately, recent field studies have documented the pre-breeding, breeding, and post-breeding activity profiles of free-ranging A. carolinensis (see Introduction). By integrating these field data with our observations on captive 
subjects, we can revisit our initial predictions and suggest likely functions for male and female signalling, and how signal use and recipient responses may affect male and female fitness.

\section{Predictions}

\section{No courtship-specific displays}

Our first prediction was supported. The lack of any courtship-specific displays is consistent with the species' mating system. Since both sexes disperse simultaneously from overwintering sites into habitat prior to the breeding season (Jenssen et al., 2001), males and females are essentially within sight of one another as pre-reproductive neighbours. Thus, at the onset of reproduction, neither sex needs to search for or attract mates with a long-distance signal. Furthermore, field data of Nunez et al. (1997) and Jenssen \& Nunez (1998) suggest that male fitness is not dependent on the design of displays to attract females or influence female mating decisions. If female choice (i.e. intersexual selection) were influencing display evolution in A. carolinensis, one would expect to find a courtship-unique male display, or at least some prominent modification to headbob displays used exclusively during courtship. However, the physical features of the three display types as performed by courting males are identical to those given in other social contexts as well as by females (Lovern et al., 1999; Jenssen et al., 2000).

The closest potential courtship-specific signal behaviour we observed for males were the shudderbobs that were appended to a fourth of male displays (Table 2, Fig. 5). Though some investigators have used shudderbobs (also called 'rapid nods') as a criterion with which to identify 'the courtship display' of captive male A. carolinensis (e.g. Greenberg \& Crews, 1983), freeranging males frequently perform displays that end in shudderbobs when advertising and patrolling their territory (Jenssen, unpubl. field data). In addition, males of other lizard species are known to use shudderbobs during consexual and non-directed contexts, as well as during courtship (e.g. Jenssen, 1977, 1979; Jenssen \& Rothblum, 1977; Ruby, 1977). That males of many species use shudderbobs in a variety of social contexts argues against this modifier being an exclusive signal for either A. carolinensis or for the courtship context.

The only courtship-specific signal performed by females was a neck-bend posture, which occurred during four different encounters and prior to two 
on-camera copulations. Neck-bends have been observed for both captive and free-ranging females of $A$. carolinensis (Crews, 1973a; Nunez et al., 1997 ) and occurs as a prelude to the precopulatory neck hold by males. The consistent co-occurrence of neck-bend and copulation reasonably implies that this posture is a sexual invitation by a receptive female.

\section{Intrasexually selected display structure}

Our second prediction, that displays used during the heterosexual context should be similar in structure to displays used during non-directed and consexual contexts, was also supported and followed the expectation of an evolutionary model by Berglund et al. (1996). Type A, B, and C display patterns are essentially identical across all social contexts. Therefore, the question arises as to which social context, consexual (inference for intrasexual selection) or heterosexual (inference for intersexual selection), most affects the design of displays and the size of the display repertoire of $A$. carolinensis. The species' mating system (see Introduction) suggests that male fitness, and hence selection on male signal structure and use, is primarily affected by the outcome of inter-male aggression over long-term access to females. Therefore, intrasexual selection on males should primarily influence signal traits, such that displaying confers an advantage to the signaller by facilitating the defence or takeover of territories. In contrast to males, female fitness seems little affected by the outcome of consexual female interactions (see Introduction). Thus, female signal traits should be less influenced by intrasexual selection than those of males. The differing intensity of intrasexual selection on males and females predicts that signal structure and/or use during intermale and inter-female aggressive contests should be sexually dimorphic, a prediction strongly supported by A. carolinensis (Jenssen et al., 2000; Table 2).

From the design features of the displays of A. carolinensis, we can also infer the effects of intrasexual selection. Most obvious is the dewlap. For the average sized male, the area of the extended dewlap is extensive and sevenfold larger than that of the average sized female $\left(1.52 \mathrm{~cm}^{2}\right.$ versus $0.22 \mathrm{~cm}^{2}$; Jenssen et al., 2000). The large, sexually dimorphic male dewlap would effectively increase display broadcast distance over that of a female dewlap, an obvious benefit to males who continuously advertise and defend the boundaries of large territories (Jenssen et al., 1995). In addition, because dewlap 
size is an honest indicator of male body size (Jenssen et al., 2000) and relative body size of males usually predicts aggressive outcomes (Tokarz, 1985), a large dewlap may intimidate consexual rivals, especially where combatants use display modifiers (e.g. sagittal compression, gular expansion, raised crest; Table 2) to deceitfully appear larger. For females, intrasexual selection for an enlarged dewlap as a feature designed for consexual contests would be unexpected given that neighbouring females tolerate overlapping home ranges, infrequently interact, and do not advertise their lightly defended territories (Nunez et al., 1997; Jenssen \& Nunez, 1998; Jenssen et al., 2000). The small dewlap of females reflects little selection for extended visibility or stimulus enhancement, regardless of possible signal function.

From the use and size of the display repertoire of $A$. carolinensis, we can infer further effects of intrasexual selection. Among the various social contexts, it is only during consexual encounters between adult males that all three display types are used with high frequency (Table 2). We suggest that this frequent use of all display types reflects the primary context in which multiple displays are most strongly selected. Further, inter-male contests involve ritualized sequences of behaviours in which the three display types are predictably orchestrated. Initially, males exchange displays at a distance, primarily using volleys of $\mathrm{C}$ displays with dewlap extensions. The second stage involves approach and increased risk; now males proportionally increase A and B displays, while infrequently signalling in volleys of displays and rarely extending their dewlaps. The final stage concludes with jaw sparring and jaw locking (e.g. Greenberg \& Noble, 1944; DeCourcy \& Jenssen, 1994; Table 2). By contrast, female-female contests lack the signal complexities and ritualization of male contests (Jenssen et al., 2000; Table 2), and resemble the social signalling of juveniles (Lovern, 2000; Table 2). Therefore, we suggest that $A$. carolinensis evolved a repertoire of multiple display types through the effects of intrasexual selection on males. Frequent and escalated intermale contests that significantly influenced male fitness may have lead to the evolution of successive display types for intimidation (Jenssen, 1977, 1978; Ord et al., 2001). Supporting evidence for this evolutionary inference comes from a comparative study of lizard species, where male-biased sexual size dimorphism (an indicator of intrasexual selection) is significantly correlated with signal repertoire size (Ord et al., 2001).

Conversely, evidence for intersexual selection on the evolution of heterosexual displays is weak. First, there appears to be little opportunity for mate 
choice by female $A$. carolinensis during home range settlement (Jenssen et al., 2001), or after home ranges are established (Jenssen \& Nunez, 1998). Second, attempts to experimentally demonstrate female mating preferences by A. carolinensis have been equivocal (Andrews, 1985b; MacDonald \& Echternacht, 1991; review by Tokarz, 1995). Third, male signal use during heterosexual interactions, as an indicator of selection pressure, would have little selective influence on signal evolution in A. carolinensis. Despite the three display types in their repertoire, males predominately used type $\mathrm{C}$ displays during interactions with females, and displayed four-fold less frequently and with shorter volleys than during consexual interactions (Table 2).

Sexually dimorphic display use

Our third prediction was supported in a dramatic manner. During heterosexual interactions males and females used an antithetical pattern of signalling. First, males performed predominately type C displays (89\%), whereas females performed mostly $\mathrm{A}$ and B displays (48\% and $50 \%$, respectively; Fig. 6, Table 2). Second, males extended the dewlap with almost all displays (98\%), whereas females rarely extended the dewlap with displays $(<2 \%$; Table 2). Third, males performed $80 \%$ of displays in volleys of two or more sequenced displays, whereas females performed only $12 \%$ of displays in volleys (Table 2). Last, males concluded $22 \%$ of displays with shudderbobs, whereas females never used shudderbobs when displaying (Fig. 5, Table 2).

Sexual identification would be the most obvious function for the divergent signalling patterns of males and females. However, the degree of sexual dimorphic signalling seems overly redundant, and even imprecise for this purpose. Consider, as a more parsimonious pattern to satisfy the primary criteria for mating (i.e. species and sexual identity), that both sexes could simply use one display type with dewlap extension. Species identification would be accomplished because any one of the display types is a stereotyped, species-specific signal shared by individuals and populations (Lovern et al., 1999), and sex identification would be unequivocally accomplished by extending the sexually size dimorphic dewlap (Jenssen et al., 2000). When displaying to females, males appear to follow this simple signalling pattern for species and sex identification by using $\mathrm{C}$ displays with dewlap extension. However, females displaying to males use an antithetical and more complex approach to species and sex identification by using A and B displays without dewlap extension. Female display usage confirms species identification, 
but the omission of an extended dewlap withholds a non-ambiguous signal for sex identification. We suggest that females diverge from an expected pattern of heterosexual signalling, using a more ambivalent system than that of males, because there may be a secondary benefit for females to do so.

\section{Female mimicry hypothesis}

Based on reasonable, circumstantial evidence, we propose the following hypothesis. Demographically, three reproductive classes exist in the A. carolinensis mating system: large, territorial males (about a third of adult male population); adult females that reside within the patrol areas of territorial males; and smaller adult males that cannot successfully defend a territory containing females. Because most small males are inconspicuous, we have little field data on their activity patterns or signalling behaviour. However, we have captured small males near, and occasionally inside, territories defended by larger territorial males, suggesting that some small males reside covertly near or within territories of larger males. Further, some offspring of females residing within large-male territories have been fathered by small males captured from these same territories (Passek, 2002). Thus, by residing in close proximity to territorial males, 'covert males' benefit by being in good habitat, close to mating opportunities, and in position to take over a territory if a territorial male disappears or becomes disabled. The cost of being covert would be eviction by a competitively superior territorial male. However, this cost could be minimized if, when detected and signalled to by a territorial male, a covert male would signal ambiguously about its sexual identity. A covert male should be selected to: (1) avoid male-typical courtship signals (e.g. C displays); and, (2) never extend the dewlap, a sexual identity signal that cannot be faked. In contrast, territorial males should be selected to display their sex honestly (i.e. with dewlap extension) when approaching a conspecific of either sex, because there are no benefits to do otherwise.

If covert males gain some direct benefit (i.e. retaining residency) by signalling like females, then resident females should also receive an indirect benefit. Because mate selection by females is basically a passive process (i.e. neutral-mate-choice model, Jenssen et al., 2001), mating with covert males would provide a secondary source of sperm to females, and allow cryptic mate choice through sperm competition (Birkhead, 1998). An increasing number of studies show that females in socially monogamous and polygynous mating systems may mate with multiple males. By doing so, females 
can receive direct benefits such as increased nuptial resources and/or paternal investment (Thornhill, 1976; Soltis \& McElreath, 2001), and/or indirect benefits such as avoiding infertile sperm or genetic incompatibility, increasing the viability, genetic diversity, and quality of offspring, and facilitating sperm competition (Zeh \& Zeh, 1996; Jennions \& Petrie, 2000; Tregenza \& Wedell, 2000).

In spite of male territorial defence, life history traits of female A. carolinensis facilitate polyandry and sperm competition. Females store sperm up to seven months, repeatedly copulate 1-2 times per week, and lay singleegg clutches about every week for four months (Fox, 1963; Andrews, 1985a; Michaud, 1990; Nunez et al., 1997). However, territorial monitoring and defence by the resident male limits the opportunity for extra-male copulations by resident females to two basic options. Females can either visit a neighbouring male's territory, or accept occasional copulations from small covert males that successfully avoid detection and eviction by the resident territorial male. The latter option is facilitated (i.e. indirectly selected) if females signal as they do, thus, permitting a directly selected mechanism (i.e. kleptogamy) for less-competitive covert males to gain mating opportunities through female mimicry.

Kleptogamy through female mimicry has been documented for small males in a variety of taxa, including insects (Forsyth \& Alcock, 1990; Harari et al., 2000), fish (Ruchon et al., 1995; Goncalves et al., 1996; Oliveira \& Almada, 1998; Uglem et al., 2001), birds (Hakkarainen et al., 1993; Saetre \& Slagsvold, 1996; Langmore \& Bennett, 1999), snakes (Mason \& Crews, 1985; Shine et al., 2001), a salamander (Howard et al., 1997), and an Anolis lizard (Trivers, 1976). Although we lack direct field evidence to support our female mimicry hypothesis, we offer several observations from laboratory studies consistent with this type of deception. First, captive males of A. carolinensis engage in homosexual courtship and copulations (e.g. Noble \& Bradley, 1933; Evans, 1938; Greenberg \& Noble, 1944; Crews, 1973b; Cooper 1977), suggesting a degree of sexual misidentification and deception between males. Second, signalling between males of A carolinensis during laboratory studies also supports sexual deception. Paired with a smaller male, a larger male displays with dewlap extensions, while the smaller male displays without dewlap extensions (e.g. Crews, 1973b, 1975; Cooper, 1977, 1979; Sigmund, 1978). Unaware of A, B and C display types of A. carolinensis, past investigators interpreted signals of captive lizards in terms of 
social hierarchies (e.g. larger males were described as 'dominant' towards smaller 'subordinate' males, and displays given by females and small males without dewlap extension were termed 'subordinate nodding'; Crews, 1975). However, these laboratory observations could also be interpreted as evoking our suggested adaptive signalling by territorial males $(\mathrm{C}$ displays with dewlap extension) and females and covert males (A and B displays without dewlap extension). Our female mimicry hypothesis for $A$. carolinensis could be tested by analyzing display exchanges between female-sized males and larger males with territorial status. The protocol could include both smallmale introductions into territories of free-ranging males, and introductions into large enclosures containing complex habitat, females, and a large resident male.

\section{Additional signal functions}

Species discrimination

Each of the three display types of $A$. carolinensis is stereotypical, speciesspecific, and could function as a species discrimination signal. Since Carpenter \& Grubitz (1961) first quantified headbob displays of lizards, most lizard species examined have been found to possess stereotypic and species-typical display cadence patterns (Carpenter, 1986). The idea that species-specific headbob displays serve as reproductive isolating mechanisms was strongly advanced for Anolis species because of the added nuance of species-typical dewlap colours among parapatric and sympatric congeners (e.g. Ruibal, 1967; Rand \& Williams, 1970; Webster \& Burns, 1973). However, experimental evidence for display signals as a criterion of species identification is lacking. Of the few studies that examined female preferences for males with conspecific displays and/or dewlap colour, only two studies supported a species discrimination function (e.g. Jenssen, 1970; Sigmund, 1978), while three others did not (e.g. Crews, 1975; MacDonald \& Echternacht, 1991; Jenssen, 1996). Some authors suggested that male anoles use displays to discriminate conspecifics from sympatric congeners during inter-male encounters (e.g. Ortiz \& Jenssen, 1982; Losos, 1985; Macedonia \& Stamps, 1994; Macedonia et al., 1994).

Selection for a species discrimination function for the display signals of $A$. carolinensis would be expected to be relaxed, however, because the species has been the only anole (disregarding recent exotic introductions in 
Florida) endemic to the continental United States for millions of years (Buth et al., 1980). Nonetheless, strong stabilizing selection on signal behaviour must occur because geographically disjunct populations of A carolinensis (e.g. Georgia, Florida, and Hawaii) all share the same three species-specific display types with relatively minor inter-population differences (Lovern et al., 1999), despite an extensive mainland distribution (approximately 1.9 million $\mathrm{km}^{2}$, McGeveran, 2002) that holds ample opportunity for alternative selective directions (e.g. varying habitat, predator pressure, and inter-deme isolation) or genetic drift on display phenotypes among local populations. In this study, we have argued that the number and structure of display types in the A. carolinensis repertoire reflect intrasexual selection (i.e. male fitness advanced through signaling during consexual activities), rather than intersexual selection (i.e. male fitness advanced through signalling during heterosexual activities). Because courtship-based selection is an unlikely explanation for the uniformity of male and female displays, we suspect that a stabilizing influence common to all populations of $A$. carolinensis may occur as a result of inter-male competition, however, the nature of this selection is currently unclear.

\section{Individual discrimination}

Variation in headbob cadence patterns between different individuals could serve as a cue for individual recognition (e.g. Stamps \& Barlow, 1973; Crews, 1975; Jenssen, 1971, 1977; Sigmund, 1978; Carpenter, 1982; Martins, 1991). Despite stereotyped display performances, inter-subject differences among A. carolinensis displays were sufficient for discriminant statistical procedures to successfully assign most individual display performances to their respective displayer. However, because of relatively small variance in display units, we do not consider that displays, per se, are being selected for displayer identity. If displayers benefit by uniquely displaying to conspecifics (i.e. selection on the displayer), then display structure would show much greater inter-individual variation than intra-individual variation, and this prediction is not supported (Fig. 4). If individual recognition occurs in A. carolinensis, and is mediated in part by display structure, then we suggest that the benefit of such recognition rests with the display recipient (i.e. selection on the recipient). Receivers would then be selected for perceptual acuity and learning of small variations in display cadence, in conjunction 
with other traits, to discriminate among individuals. There is mounting evidence that some lizards, including A. carolinensis, can discriminate among individual conspecifics. As examples, males can discriminate between familiar and novel females (Cooper, 1985; Tokarz, 1992; Orrell \& Jenssen, 1998, 2002) and among male neighbours and prior rivals (e.g. Qualls \& Jaeger, 1991; Fox \& Baird, 1992; Olsson, 1994; Whiting, 1999; Lopez \& Martin, 2001; Husak \& Fox, 2003). However, experimental evidence that individual recognition is being cued by display structure remains weak.

\section{Overview}

We make three broad generalities for the display behaviour of A. carolinensis: (1) all social contexts are served by a common repertoire of the same three display types; (2) intrasexual selection appears to have the greatest influence on reproductive success and, by logical extension, on display structure and repertoire; and (3) the sexes use a divergent pattern of intersexual signalling that facilitates sex recognition, but also suggests a deceptive signalling strategy favouring an alternative mating strategy for females and small males. These three generalizations integrate with the species' social organization. To begin, use of the same display types during both hetero- and consexual social contexts indicates only one of these contexts has primarily influenced the uniform display cadence patterns and number of display types that occur across different kinds of social interactions. We infer from the species' female-defence polygynous mating system, that intrasexual selection appears to have the most effect on male reproductive success (i.e. as facilitated by male signalling traits) through the outcome of territorial contests. In addition, female reproductive success within this mating system appears to be disassociated from active mate choice, and thus female choice as an agent of intersexual selection would not have much influence on male signalling traits. That mainland A. carolinensis had no other sympatric congeners in recent history diminishes another condition for intersexual selection; females need not be choosy about display traits of prospective mates to avoid outbreeding. Finally, we found a dimorphic pattern of heterosexual signalling: territorial males signalled sexual identity in a parsimonious and unequivocal manner, while females used signals that were sexually ambiguous. This excessive divergence in female signalling stimulated our hypothesis of permissive female-mimicry, which represents a logical integration of female and 
small male fitness options within a mating system overtly controlled by large males. Without an understanding of the A. carolinensis mating system, our inferences for the sexually dimorphic signal pattern would have concluded with simple sexual identity.

\section{References}

Andersson, M. (1994). Sexual selection. - Princeton Univ. Press, Princeton, New Jersey.

Andrews, R.M. (1985a). Oviposition frequency of Anolis carolinensis. - Copeia 1985, p. $259-262$.

— - (1985b). Mate choice by females of the lizard, Anolis carolinensis. — J. Herpetol. 19, p. 284-289.

Barlow, G. (1977). Modal action patterns. — In: How animals communicate (T.A. Sebeok, ed.). Indiana University Press, Bloomington, Indiana, p. 98-134.

Bateman, A.J. (1948). Intra-sexual selection in Drosophila. - Heredity 2, p. 349-368.

Bels, V.L. (1990). The mechanism of dewlap extension in Anolis carolinensis (Reptilia: Iguanidae) with histological analysis of the hyoid apparatus. - J. Morphol. 206, p. 225244.

Berglund, A., Bisazza, A. \& Pilastro, A. (1996). Armaments and ornaments: an evolutionary explanation of traits of dual utility. - Biol. J. Linnean Soc. 58, p. 385-399.

Birkhead, T.R. (1998). Cryptic female choice: criteria for establishing female sperm choice. — Evolution 52, p. 1212-1218.

Bradbury, J.W. \& Vehrencamp, S.L. (1998). Principles of animal communication. — Sinauer Associates, Sunderland, Massachusetts.

Buth, D.G., Gorman, G.C. \& Lieb, C.S. (1980). Genetic divergence between Anolis carolinensis and its Cuban progenitor, Anolis porcatus. - J. Herpetol. 14, p. 279-284.

Carpenter, C.C. (1982). The aggressive displays of Iguanine lizards. - In: Iguanas of the world, their behavior, ecology and conservation (G.M. Burghardt \& A.S. Rand, eds). Noyes Publications, Park Ridge, New Jersey, p. 215-231.

- - (1986). An inventory of the Display-Action-Patterns in lizards. - Smiths. Herpetol. Inf. Serv. 68, p. 1-19.

— — \& Grubitz, G. (1961). Time-motion study of a lizard. — Ecology 42, p. 123-128.

Cooper, W.E., Jr. (1977). Information analysis of agonistic behavioral sequences in male Iguanid lizards, Anolis carolinensis. - Copeia 1977, p. 721-735.

- - (1979). Variability and predictability of courtship in Anolis carolinensis (Reptilia, Lacertilia, Iguanidae). - J. Herpetol. 13, p. 233-243.

- - (1985). Female residency and courtship intensity in a territorial lizard, Holbrookia propinqua. - Amphibia-Reptilia 6, p. 63-69.

Crews, D. (1973a). Coition-induced inhibition of sexual receptivity in female lizards (Anolis carolinensis). - Physiol. Behav. 11, p. 463-468.

- - (1973b). Social factors associated with the male in the control of reproduction in the female lizard Anolis carolinensis. the role of courtship and aggression. - $\mathrm{PhD}$ thesis. Rutgers University, New Brunswick, New Jersey.

- - (1975). Inter- and Intraindividual variation in display patterns in the lizard Anolis carolinensis (Reptilia, Lacertilia, Iguanidae). - J. Herpetol. 13, p. 233-243. 
Davies, N.B. (1991). Mating systems. — In: Behavioural ecology: An evolutionary approach, 3rd ed. (J.R. Krebs \& N.B. Davies, eds). Blackwell Publishing, Oxford, United Kingdom, p. 263-294.

DeCourcy, K.R. \& Jenssen, T.A. (1994). Structure and use of male territorial headbob signals by the lizard Anolis carolinensis. - Anim. Behav. 47, p. 251-262.

Emlen, S. \& Oring, L. (1977). Ecology, sexual selection, and the evolution of mating systems. - Science 197, p. 215-223.

Evans, L.T. (1938). Courtship behavior and sexual selection of Anolis. — J. Comp. Psychol. 26, p. 475-491.

Font, E. \& Rome, L. (1990). Functional morphology of dewlap extension in the lizard Anolis equestris (Iguanidae). - J. Morphol. 206, p. 245-258.

Ford, N.B. (1986). The role of pheromone trails in the sociobiology of snakes. - In: Chemical signals in vertebrates (D. Duvall, D. Müller-Schwarze \& R.M. Silverstein, eds). Plenum, New York, p. 261-278.

Forsythe, A. \& Alcock, J. (1990). Female mimicry and resource defense polygyny by males of a tropical rove beetle, Leistrotrophus versicolor (Coleoptera: Staphylinidae). - Behav. Ecol. Sociobiol. 26, p. 325-330.

Fox, W. (1963). Special tubules for sperm storage in female lizards. - Nature 198, p. 500501.

Fox, S.F. \& Baird, T.A. (1992). The dear enemy phenomenon in the collared lizard, Crotaphytus collaris, with a cautionary note on experimental methodology. - Anim. Behav. 44, p. 780-782.

Goncalves, E.J., Almada, V.C., Oliveira, R.F. \& Santos, A.J. (1996). Female mimicry as a mating tactic in males of the blenniid fish Salaria pavo. — J. Marine Biol. Assoc. U.K. 76, p. 529-538.

Greenberg, B. \& Noble, G.K. (1944). Social behavior of the American chameleon (Anolis carolinensis Voigt). — Physiol. Zool. 17, p. 392-439.

Greenberg, N. (1977). A neuroethological study of display behavior in the lizard Anolis carolinensis (Reptilia, Lacertilia, Iguanidae). - Amer. Zool. 17, p. 392-439.

— — \& Crews, D. (1983). Physiological ethology of aggression in amphibians and reptiles. — In: Hormones and aggressive behavior (B.B. Svare, ed.). Plenum Press, New York, p. 469-506.

Hakkarainen, H., Korpimaki, H.E. \& Palokangas, P. (1993). Delayed maturation in plumage color - evidence for the female-mimicry hypothesis in the kestrel. - Behav. Ecol. Sociobiol. 33, p. 247-251.

Harari, A.R., Brockmann, H.J. \& Landolt, P.J. (2000). Intrasexual mounting in the beetle Diaprepes abbreviatus (L.). — Proc. Royal Soc. London B 267, p. 2071-2079.

Howard, R.D. (1978). The evolution of mating strategies in bullfrogs, Rana catesbeiana. Evolution 32, p. 850-871.

— —, Moorman, R.S. \& Whiteman, H.H. (1997). Differential effects of mate competition and mate choice on eastern tiger salamanders. - Anim. Behav. 53, p. 1345-1356.

Husak, J.F. \& Fox, S.F. (2003). Adult male collared lizards, Crotaphytus collaris, increase aggression towards displaced neighbours. Anim. Behav. 65, p. 391-396.

Jennions, M.D. \& Petrie, M. (2000). Why do females mate multiply? A review of the genetic benefits. - Biol. Rev. Cambridge Phil. Soc. 75, p. 21-64.

Jenssen, T.A. (1970). Female response to filmed displays of Anolis nebulosus (Sauria, Iguanidae). - Anim. Behav. 18, p. 640-647. 
- - (1971). Display analysis of Anolis nebulosus. (Sauria, Iguanidae). - Copeia 1971, p. 197-209.

— - (1977). Evolution of anoline lizard display behavior. - Amer. Zool. 17, p. 203-215.

- - (1978). Display diversity in Anoline lizards and problems of interpretation. - In: Behavior and neurology of lizards (N. Greenberg \& P.D. MacLean, eds). National Institute of Mental Health, Rockville, Maryland, p. 269-285.

— - (1979). Display modifiers of Anolis opalinus (Lacertilia: Iguanidae). — Herpetologica 35, p. 21-30.

- - (1996). A test of assortative mating between sibling lizard species, Anolis websteri and A. caudalis, in Haiti. - In: Herpetology of the West Indies: a symposium in honor of Albert Schwartz (R. Powell \& R. Henderson, eds). SSAR Contributions to Herpetology Series, Ithaca, New York, p. 303-315.

- -, Lovern, M.B. \& Congdon, J.D. (2001). Field-testing the protandry-based mating system for the lizard, Anolis carolinensis: does the model organism have the right model? - Behav. Ecol. Sociobiol. 50, p. 162-172.

— - Greenberg, N. \& Hovde, K.A. (1995). Behavioral profile of free-ranging male lizards, Anolis carolinensis, across breeding and post-breeding seasons. - Herpetol. Monogr. 9, p. 41-62.

— — \& Nunez, S.C. (1998). Spatial and breeding relationships of the lizard, Anolis carolinensis: evidence of intrasexual selection. - Behaviour 135, p. 981-1003.

— - Orrell, K.S. \& Lovern, M.B. (2000). Sexual dimorphisms in aggressive signal structure and use by a polygynous lizard, Anolis carolinensis. - Copeia 2000, p. 140-149.

— — \& Rothblum, L.M. (1977). Display repertoire analysis of Anolis townsendi (Sauria: Iguanidae) from Cocos Island. - Copeia 1977, p. 103-109.

Langmore, N.E. \& Bennett, A.T.D. (1999). Strategic concealment of sexual identity in an estrildid finch. - Proc. Royal Soc. London B 266, p. 543-550.

Licht, P. (1971). Regulation of the annual testis cycle by photoperiod and temperature in the lizard Anolis carolinensis. - Ecology 52, p. 540-252.

Lightbody, K.P. \& Weatherhead, P.J. (1988). Female settling patterns and polygyny: tests of a neutral-mate-choice hypothesis. - Amer. Nat. 132, p. 20-33.

Lopez, P. \& Martin, J. (2001). Fighting rules and rival recognition reduce costs of aggression in male lizards, Podarcis hispanica. - Behav. Ecol. Sociobiol. 49, p. 111-116.

Losos, J.B. (1985). An experimental demonstration of the species-recognition role of Anolis dewlap color. - Copeia 1985, p. 905-910.

Lovern, M.B. (2000). Social and hormonal effects on the ontogeny of sex differences in behavior in the lizard, Anolis carolinensis. - PhD thesis. Virginia Polytechnic Institute and State University, Blacksburg, Virginia.

— —, Jenssen, T.A., Orrell, K.S. \& Tuchak, T. (1999). Comparisons of temporal display structure acoss contexts and populations in male Anolis carolinensis: signal stability or lability? - Herpetologica 55, p. 222-234.

MacDonald, D. \& Echternacht, A.C. (1991). Red-throated and gray-throated Anolis carolinensis: do females know the difference? - Anolis Newsletter 4, p. 92-100.

Macedonia, J.M., Evans, C.S. \& Losos, J.B. (1994). Male Anolis lizards discriminate videorecorded conspecific and heterospecific displays. - Anim. Behav. 47, p. 1220-1223.

—— \& Stamps, J.A. (1994). Species recognition in Anolis grahami: evidence from responses to video playbacks of conspecific and heterospecific displays. - Ethology 98, p. 246264. 
McGeveran, Jr., W. (2002). The world almanac and book of facts. World Almanac Education Group, Inc. New York, p. 1-1008.

Martins, E.P. (1991). Individual and sex differences in the use of push-up display by the sagebrush lizard, Sceloporus graciosus. - Anim. Behav. 41, p. 403-416.

Mason, R.T. \& Crews, D. (1985). Female mimicry in garter snakes. — Nature 316, p. 59-60.

Michaud, E.J. (1990). Geographic variation of life history traits in the lizard, Anolis carolinensis. - PhD dissertation, University of Tennessee, Knoxville, Tennessee.

Noble, G.K. \& Bradley, H.T. (1933). The mating behavior of lizards: its bearing on the theory of sexual selection. - Ann. New York Acad. Sci. 35, p. 25-100.

Nunez, S.C., Jenssen, T.A. \& Ersland, K. (1997). Female activity profile of a polygynous lizard (Anolis carolinensis): evidence of intersexual asymmetry. - Behaviour 134, p. 205-223.

Oliveira, R.F. \& Almada, V.C. (1998). Mating tactics and male-male courtship in the lekbreeding cichlid Oreochromis mossambicus. — J. Fish Biol. 52, p. 1115-1129.

Olsson, M. (1994). Rival recognition affects male contest behavior in sand lizards (Lacerta agilis). - Behav. Ecol. Sociobiol. 35, p. 249-252.

Ord, T.J., Blumstein, D.T. \& Evans, C.S. (2001). Intrasexual selection predicts the evolution of signal complexity in lizards. - Proc. Royal Soc. London B 268, p. 737-744.

Orrell, K.S. (2002). Male mate preference, heterosexual communication, and reproductive energetics of the polygynous lizard, Anolis carolinensis. $-\mathrm{PhD}$ dissertation, Virginia Polytechnic Institute and State University, Blacksburg, Virginia.

— — \& Jenssen, T.A. (1998). Display behavior of Anolis bahorucoensis. an anole with a diminutive dewlap. - Caribbean J. Sci. 34, p. 113-125.

- $-\&-\ldots$ (in press). Male mate choice by the lizard, Anolis carolinensis. a preference for novel females. - Anim. Behav.

Ortiz, P.R. \& Jenssen, T.A. (1982). Interspecific aggression between lizard competitors, Anolis cooki and Anolis cristatellus. - Z. Tierpsychol. 60, p. 227-238.

Partridge, L. \& Endler, J.A. (1987). Life history constraints on sexual selection. — In: Sexual selection: testing the alternatives (J.W. Bradbury \& M.B. Andersson, eds). Wiley, Chichester, United Kingdom, p. 265-277.

Passek, K. (2002). Extra-male paternity and sperm competition in the lizard Anolis carolinensis. - PhD dissertation, Virginia Polytechnic Institute and State University, Blacksburg, Virginia.

Qualls, C.P. \& Jaeger, R.G. (1991). Dear enemy recognition in Anolis carolinensis. - J. Herpetol. 25, p. 361-363.

Rand, A.S. \& Williams, E.E. (1970). An estimation of redundancy and information content of anole dewlaps. - Amer. Nat. 104, p. 9-103.

Rice, W.R. (1989). Analyzing tables of statistical tests. — Evolution 43, p. 223-225.

Ruby, D.E. (1977). The function of the shudder displays in the lizard Sceloporus jarrovi. Copeia 1977, p. 110-114.

_- (1984). Male breeding success and differential access to females in Anolis carolinensis. - Herpetologica 40, p. 272-280.

Ruchon, F., Laugier, T. \& Quignard, J.P. (1995). Alternative male reproductive strategies in the peacock blenny. - J. Fish Biol. 47, p. 826-840.

Ruibal, R. (1967). Evolution and behavior in West Indian anoles. — In: Lizard ecology: a symposium (W.W. Milstead, ed.). University of Missouri Press, Columbia, Missouri, p. 116-140. 
SAS Institute Inc. (1989). SAS/STAT user's guide, version 6, 4th Ed., Vol. 1 \& 2. — SAS Institute Inc., Cary, North Carolina.

Saetre, G.P. \& Slagsvold, T. (1996). The significance of female mimicry in male contests. Amer. Nat. 147, p. 981-995.

Searcy, W.A. \& Andersson, M. (1986). Sexual selection and the evolution of song. - Ann. Rev. Ecol. Syst. 17, p. 507-533.

— — \& Yawasaka, K. (1994). Polygyny and sexual selection in red-winged blackbirds. Princeton University Press, Princeton, New Jersey.

Shine, R., Phillips, B., Waye, H., LeMaster, M. \& Mason, R.T. (2001). Benefits of female mimicry in snakes. - Nature 414, p. 267.

Sigmund, W.R. (1978). The analysis of visual displays in the lizard, Anolis carolinensis. $\mathrm{PhD}$ dissertation, Indiana University, Bloomington, Indiana.

Soltis, J. \& McElreath, R. (2001). Can females gain extra paternal investment by mating with multiple males? A game theoretic approach. - Amer. Nat. 158, p. 519-529.

Stamps, J.A. \& Barlow, G.W. (1973). Variation and stereotypy in the displays of Anolis aeneus (Sauria: Iguanidae). - Behaviour 47, p. 67-94.

Sutherland, W.J. (1996). From individual behaviour to population ecology. Oxford University Press, New York.

Thornhill, R. (1976). Sexual selection and nuptual feeding behavior in Bittacus apicalis (Insecta: Mecoptera). — Amer. Nat. 110, p. 529-548.

— — \& Alcock, J. (1983). The evolution of insect mating systems. — Harvard University Press, Cambridge, Massechusetts.

Tinbergen, N. (1951). The study of instinct. — Oxford University Press, New York.

Tinkle, D.W. (1967). The life and demography of the side-blotched lizard, Uta stansburiana. - Misc. Publ. Mus. Zool., University of Michigan 132, p. 1-182.

Tokarz, R.R. (1985). Body size as a factor determining dominance in staged agonistic encounters between male brown anoles (Anolis sagrei). - Anim. Behav. 33, p. 746-753.

— - (1992). Male mating preference for unfamiliar females in the lizard, Anolis sagrei. Anim. Behav. 44, p. 843-849.

— - (1995). Mate choice in lizards: a review. — Herpetol. Monogr. 9, p. 17-40.

Tregenza, T. \& Wedell, N. (2000). Genetic compatibility, mate choice and patterns of parentage: invited review. - Molecular Ecol. 9, p. 1013-1027.

Trivers, R. (1976). Sexual selection and resource-accruing abilities in Anolis garmani. Evolution 30, p. 253-269.

Uglem, I., Galloway, T.F., Rosenqvist, G. \& Folstad, I. (2001). Male dimorphism, sperm traits and immunology in the corkwing wrasse (Symphodus melops L.). - Behav. Ecol. Sociobiol. 50, p. 511-518.

Webster, T.P. \& Burns, J.M. (1973). Dewlap color variation and electrophoretically detected sibling species in a Haitian lizard, Anolis brevirostris. — Evolution 27, p. 368-377.

Whiting, M.J. (1999). When to be neighbourly: differential agonistic responses in the lizard Platysaurus broadleyi. - Behav. Ecol. Sociobiol. 46, p. 210-124.

Wiley, R.H. \& Poston, J. (1996). Indirect mate choice, competition mates, and coevolution of the sexes. - Evolution 50, p. 1371-1381. 
Zeh, J.A. \& Zeh, D.W. (1996). The evolution of polyandry I: intragenomic conflict and genetic incompatibility. - Proc. Royal Soc. London B 263, p. 1711-1717. 